V.I. Milykh, L.V. Shilkova

\title{
CHARACTERISTICS OF A CYLINDRICAL INDUCTOR OF A ROTATING MAGNETIC FIELD FOR TECHNOLOGICAL PURPOSES WHEN IT IS POWERED FROM THE MAINS AT A GIVEN VOLTAGE
}

Introduction. A computational analysis of the characteristics of an inductor of a rotating magnetic field for technological purposes is presented. The design of its stator is borrowed from a three-phase induction motor. The cylindrical cavity inside the stator is occupied by a working chamber into which a granular or liquid processed substance is loaded. The processing is carried out with elongated ferromagnetic elements moving with a magnetic field. Problem. The purpose of the article is a study of the electromagnetic, phase, and energy characteristics of an inductor at its operation under load mode with a given voltage of the stator winding. Methodology. The study is performed on the basis of numerical calculations of the magnetic field, taking into account the anisotropy of the low-magnetic medium in the working chamber. Its discrete medium is represented homogeneous with different magnetic permeabilities on mutually perpendicular axes. The technique of transition from the results of the magnetic field calculation to the electric, magnetic, phase and energy parameters of the inductor is given. This is facilitated by the electrical equivalent circuit of the stator phase winding, the equilibrium equation of its electrical quantities, vector diagrams and an iterative method for determining the current at a given voltage. Results. Mutual dependencies of a number of inductor parameters are formed into a family of characteristics exhibiting its properties in an operating mode with a changing load. Characteristics include such quantities as magnetic flux linkage of the stator winding, its current and EMF, phase shifts between them, electromagnetic torque, expended and useful power and its losses, power factor and efficiency. In this article, a feature of this mode is the stability of the stator winding voltage in the inductor. This complements the earlier studies of the inductor in the mode with stabilization of the winding current, which allows to compare these options. On the example of a test sample of an inductor, a number of its characteristics are shown, vector diagrams of its electric and magnetic quantities illustrating their mutual phase shifts are given. Practical value. The presented technique for determining the electric and magnetic quantities of the inductor and their phase relationships, and also the shown family of characteristics can contribute to increasing the design efficiency and improving the inductors of the considered type. The developed technique has the universality property, as it is capable of displaying their various circuit and constructional design parameters. References 9, figures 8 .

Key words: three-phase cylindrical inductor, working chamber, ferromagnetic elements, rotating magnetic field, numerical calculations, load mode, stable voltage, electric, magnetic and energy parameters, phase shifts.

Надано розрахунковий аналіз характеристик індуктора обертового магнітного поля технологічного призначення. Конструкція його статора запозичена у трифазного асинхронного двигуна. Циліндрична порожнина усередині статора зайнята робочою камерою, в яку завантажується сипка або рідка оброблювана речовина. Обробка відбувається довгастими феромагнітними елементами, щңо рухаються 3 магнітним полем. Викладена методика отримання електричних, магнітних $і$ енергетичних величин індуктора, яка заснована на чисельно-польових розрахунках з урахуванням магнітної анізотропії середовища, ще заповнює робочу камеру. Взаємні залежності низки величин сформовані в сім'ю характеристик, які проявляють його властивості в робочому режимі. У цій статті його особливістю є стабільність напруги обмотки статора індуктора. Це доповнює проведені раніше дослідження індуктора в режимі із стабілізацією струму обмотки, цо дозволяє порівняти такі варіанти роботи. На прикладі тестового зразка індуктора показано ряд його характеристик, приведені векторні діаграми електричних і магнітних величин, це ілюструють їх взаємні фазові зміцення. Бібл. 9, рис. 8.

Ключові слова: трифазний циліндричний індуктор, робоча камера, феромагнітні елементи, магнітне поле, що обертається, чисельні розрахунки, режим навантаження, стабільна напруга, електричні, магнітні і енергетичні параметри, фазові зсуви.

Представлен расчетный анализ характеристик индуктора вращающегося магнитного поля технологического назначения. Конструкция его статора заимствована у трехфазного асинхронного двигателя. Цилиндрическая полость внутри статора занята рабочей камерой, в которую загружается сыпучее или жсикое обрабатываемое вещество. Обработка происходит движущимися с магнитным полем продолговатыми ферромагнитными элементами. Изложена методика получения электрических, магнитных и энергетических величин индуктора, основанная на численно-полевых расчетах с учетом магнитной анизотропии среды, заполняющей рабочую камеру. Взаимные зависимости ряда величин сформированы в семейство характеристик, проявляющих его свойства в рабочем режиме. В данной статье его особенностью является стабильность напряжения обмотки статора индуктора. Это дополняет проведенные ранее исследования индуктора в режиме со стабилизацией тока обмотки, что позволяет сравнить такие варианты работы. На примере тестового образца индуктора показан ряд его характеристик, приведены векторные диаграммы электрических и магнитных величин, иллюстрирующие их взаимные фазовые смещения. Библ. 9 , рис. 8.

Ключевые слова: трехфазный цилиндрический индуктор, рабочая камера, ферромагнитные элементы, вращающееся магнитное поле, численные расчеты, режим нагрузки, стабильное напряжение, электрические, магнитные и энергетические параметры, фазовые смещения.

Introduction. In a number of industries, the technological treatment of liquid or granular substances is done with magnetic stirrers, grinders and separators [1-5].

The magnetic fields that provide this are diverse in structure and character, and rotating fields have their 
place here. They are created by an inductor, the design of which is borrowed from the stator of a three-phase induction motor [6].

A working chamber is placed in the cylindrical cavity of the stator, through which the processed substance is passed. Processing is done by ferromagnetic elements (FEs) in the form of elongated segments of steel wire, moving with a rotating field. They create the socalled «eddy layer» in the chamber [5-7]. The thin shell of the camera is made non-magnetic and therefore does not interact with the field.

From the analysis of scientific publications it follows that the study of the electromagnetic parameters of the inductor is carried out mainly on the basis of methods from the theory of magnetic circuits. However, with very large gaps and a discrete low-magnetic space inside the working chamber, the representation of the structure of the inductor in several homogeneous magnetic sections becomes problematic.

Clarification of electromagnetic calculations and improvement of the design of the inductor is possible through the use of numerical-field methods. And on this basis, in [7], studies of electromagnetic and energy parameters and the corresponding characteristics of the inductor during its operation in the load mode have already been carried out. The condition for this was the stability of the stator winding current of the inductor with appropriate regulation of its voltage. And it was also noted there that the mode of interest is a given constant voltage mode.

The goal of the paper is study of electromagnetic, phase and energy characteristics of the inductor during its operation in load mode with a given voltage of the stator winding. This is performed, as in [7], by means of numerical-field calculations taking into account the anisotropy of a low-magnetic medium in a working chamber filled with ferromagnetic elements.

Object of study. The electromagnetic system of the inductor is adopted as in [7], and here it is represented by its cross section (Fig. 1). In the calculations, the rectangular $(x, y)$ and polar $(r, \alpha)$ coordinate systems are used, and $\alpha$ is counted from the $y$ axis.

The inductor has the number of pairs of poles $p=1$, phases $m_{s}=3$, slots $Q_{s}=42$ and turns of the phase winding $N_{s}=28$. The technical conditions set the radius of the surface of the chamber $r_{r e}=0.15 \mathrm{~m}$, the axial length of the core $l_{a}=0.3 \mathrm{~m}$, its inner radius $r_{s i}=0.175 \mathrm{~m}$. The stator winding is distributed, two-layer, its relative shortening is $18 / 21$, the circuit is «star». The fill factor $K_{F e}$ of the core with electrical steel grade 2013 is 0.97 .

The rated phase voltage of the stator winding $U_{s N}=220 \mathrm{~V}$, frequency $f_{s}=50 \mathrm{~Hz}$.

A fragment of an idealized structure of FEs uniformly distributed in the working chamber is shown in Fig. 2. In general, this corresponds to the data of experimental studies on the physical model of the inductor [6]. Although the actual distribution of elements is somewhat more chaotic, idealization is necessary for organizing available calculations.

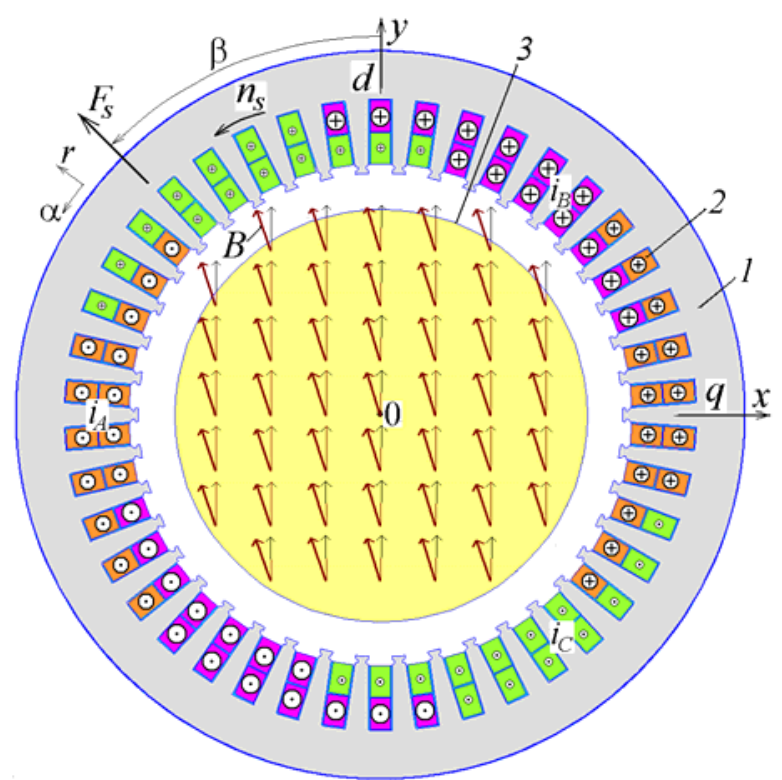

Fig. 1. The cross section of the electromagnetic system of the inductor: 1 -core; 2 -winding; 3 -surface of the working chamber

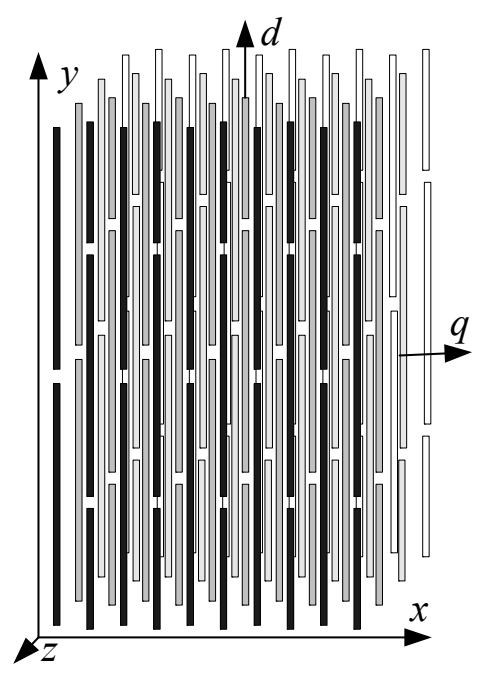

$a$

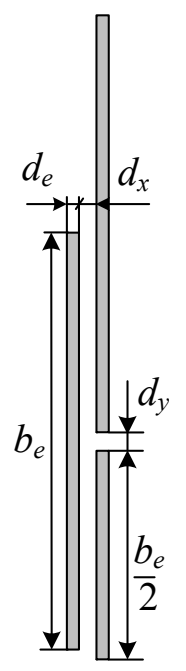

$b$
Fig. 2. Idealized structure of ferromagnetic elements $(a)$, their sizes and gaps $(b)$

For the test case, according to the notation of the quantities (Fig. 2,b), their values are taken: $d_{e}=1 \mathrm{~mm}$; $b_{e}=23.8 \mathrm{~mm} ; d_{x}=1.43 \mathrm{~mm} ; d_{y}=1 \mathrm{~mm}$, the fill factor of the chamber with elements in the plane $x y$ (Fig. 2,a) $K_{\text {Fes }}=0.35$, by volume $K_{F e v}=0.122$.

The essence of numerical field calculations. A rotating magnetic field in the inductor is excited by a symmetric three-phase system of stator winding currents (Fig. 1):

$$
\begin{gathered}
i_{A}=I_{m} \cos \left(\omega_{s} t+\beta\right) ; \quad i_{B}=I_{m} \cos \left(\omega_{s} t-2 \pi / 3+\beta\right) \\
i_{C}=I_{m} \cos \left(\omega_{s} t+2 \pi / 3+\beta\right)
\end{gathered}
$$

where $t$ is time; $I_{m}=\sqrt{2} I_{s}$ is the amplitude of the phase currents at their effective value $I_{s} ; \omega_{s}=2 \pi f_{s}$ is the angular frequency; $\beta$ is the initial phase of the currents, which gives the angular displacement of the stator winding MMF vector $F_{s}$ from the $y$ axis, necessary for a particular calculation mode. 
The instantaneous directions of currents (1) in the winding rods are shown in Fig. 1 for $t=0$ and $\beta=45^{\circ}$, the corresponding direction of the MMF vector $F_{s}$ is also given.

In the cross section of the inductor (Fig. 1), a planeparallel magnetic field is described by the well-known differential equation:

$$
\operatorname{rot}\left[\mu_{a}^{-1} \operatorname{rot}\left(\vec{k} A_{z}\right)\right]=\vec{k} J_{z}
$$

where $\vec{k}$ is the axial unit; $J_{z}, A_{z}$ are the components of the vectors of current density and magnetic vector potential along the $z$ axis; $\mu_{a}$ is the absolute magnetic permeability.

The propagation of the field is limited by the circle on the outer surface of the stator core by setting the boundary condition $A_{z}=0$.

Numerical calculations of the magnetic field are performed by the FEMM program [8] by the Finite Element Method, which is controlled by the Lua script created by analogy with [9].

The magnetic permeability $\mu_{a}$ in the laminated core of the stator and nonmagnetic medium when calculating the field is taken into account in a known manner [8]. In the working chamber, a discrete magnetic-nonmagnetic medium (Fig. 2) is represented by a continuous homogeneous medium with different magnetic permeabilities $\mu_{d}$ and $\mu_{q}$ along the longitudinal $d$ and perpendicular to it transverse $q$ axes (Fig. 1, 2). Different magnetic properties in the chamber in different directions correspond, in fact, to the magnetic anisotropy of the medium. The justification of this transition and the principle of determining the values of $\mu_{d}$ и $\mu_{q}$ are given in [7], where the relative values of the magnetic permeability $\mu_{r d}=10$ p.u.; $\mu_{r q}=1.5$ p.u. were obtained which are also used in this paper.

Test calculation of the magnetic field and the principle of operation of the inductor. In Fig. 1, the longitudinal axis $d$ coincides with the $y$ axis. Here, a priori a «snapshot» of the vectors of the magnetic flux density $\boldsymbol{B}$ and MMF $F_{s}$ is shown.

When the inductor operates under load, the angle $\beta$ is within the range $0-90^{\circ}$, and at extreme values 0 and $90^{\circ}$ there is no electromagnetic torque, and this corresponds to idle mode [7].

As a «point» example, a test calculation of the inductor in the load mode with a rated voltage $U_{s N}$ and at $\beta=45^{\circ}$ was performed. The phase current $I_{S}$ was $455 \mathrm{~A}$, which was substantiated in [7].

In Fig. 1, the bold arrows show the calculated corresponding distribution of the magnetic flux density vectors $\boldsymbol{B}$ in the conditioned mode (on one scale). They are rotated with respect to the $d$ axis in the direction of rotation of the field indicated by the arrow $n_{s}$, but they lag behind the MMF vector $F_{s}$, which «leads» the vectors of the remaining quantities. Note that in the center of the working chamber, magnetic flux density is $0.36 \mathrm{~T}$.

In idle mode, the vectors $F_{s}$ and $\boldsymbol{B}$ (thin arrows) in Fig. 1 are directed, naturally, along the longitudinal axis $d$. It can be seen that, under load and during idle, the magnetic field in the chamber is almost uniform.

It is known that elongated ferromagnetic elements tend to be located along the lines of force of the magnetic field and, thus, parallel to the magnetic flux density vectors. The processed substance entering the working chamber cannot immediately «pick up» the rotation frequency corresponding to the rotation frequency of the magnetic field $n_{s}$, and therefore is penetrated by elements moving with the field.

Therefore, due to the braking effect of the medium being processed, between the direction of the magnetic flux density vectors $\boldsymbol{B}$ of the magnetic field that rotates and the elements oriented along the $d$ axis, an angle shift must be formed. This is a prerequisite for creating the electromagnetic torque (EMT) $M_{e m}$ acting on the elements, and this determines the intensity of processing heterogeneous mixtures according to a given technological process.

In fact, it is revealed that in the considered inductor the EMT is reactive, and, therefore, its principle of operation corresponds to a synchronous reluctance motor, which was already noted in [7]. That is why - like synchronous electric machines, the longitudinal axis $d$ is assigned in the working chamber in the direction of orientation of the ferromagnetic elements, and the transverse axis $q$ is directed perpendicularly. In the steady state load conditions, these axes rotate together with the magnetic field and FEs.

Determination of magnetic, electrical and energy quantities of the inductor. The setting or calculation of such quantities is an important and necessary problem in calculating the electromagnetic and energy parameters and characteristics of the inductor, which are presented below in the text.

One of the basic values of the analysis of a number of electromagnetic parameters of the inductor is the magnetic flux linkage (MFL) $\Psi_{a}$ of the stator winding. In the FEMM program, it is determined using the Lua script $[8,9]$ with a special function.

After calculation, by scanning the phase winding with its «mask», the numerical angular function of the MFL is formed from the instantaneous structure of the magnetic field:

$$
\Psi_{k}\left(\alpha_{k}\right), k=1,2, \ldots, K,
$$

where the required number of positions $K$ is $Q_{s} / 2$.

This function is periodic, is represented by a harmonic Fourier series, and is transformed into the temporal function of the MFL, as shown in [7]. Of this series, the first harmonic is used, as is customary in electric machines:

$$
\Psi_{a}=\Psi_{m} \cos \left(\omega_{s} t+\gamma_{\psi a}\right) .
$$

By means of the law of electromagnetic induction, phase EMF of the winding is derived from (4):

$$
e_{a}=\omega \Psi_{m} \cos \left(\omega_{s} t+\gamma_{\psi a}-\pi / 2\right),
$$

whence its effective value and initial phase:

$$
E_{a}=\sqrt{2} \pi f_{s} \Psi_{m} ; \gamma_{E a}=\gamma_{\psi a}-\pi / 2 .
$$

The set of processes in the phase winding of the stator in [7] is represented by an electrical equivalent circuit, as well as by the corresponding equation of equilibrium of voltages and EMF:

$$
\underline{U}_{s}=-\underline{E}_{a}+j X \underline{I}_{s}+\left(R_{s}+R_{m a g}\right) \underline{I}_{s},
$$


where, based on (1) and (6), the complexes of current and EMF of this winding are known:

$$
\underline{I}_{s}=I_{s} e^{j \beta} ; \quad \underline{E}_{a}=E_{a} e^{j \gamma_{E a}} .
$$

Formula (7) includes the active resistance $R_{S}$ of the stator winding and the reactance of its frontal scattering $X_{v}$. They are calculated according to classical methods for calculating induction motors and amounted to: $R_{s}=9.68 \mathrm{~m} \Omega$ and $X_{v}=22 \mathrm{~m} \Omega$.

Active resistance, representing the power of magnetic losses $P_{\text {mag }}$ in the stator core, is sought by the formula:

$$
R_{\text {mag }}=P_{\text {mag }} /\left(m_{s} I_{s}^{2}\right)
$$

and such a power, as in [7], is obtained in the course of numerical-field calculation.

According to (7), the voltage complex is found in exponential form $\underline{U}_{s}=U_{s} e^{j \gamma_{U s}}$, which gives its effective value $U_{s}$. The phase shifts of the EMF $\underline{E}_{a}$ and voltage $\underline{U}_{s}$ relative to the current $\underline{I}_{s}$ are obtained through their initial phases $\gamma_{E a}$ and $\gamma_{U s}$ already determined, namely: $\varphi_{E a}=\gamma_{E a}-\beta$ and $\varphi_{s}=\gamma_{U s}-\beta$.

In the load mode of the inductor, by the test calculation of the magnetic field and parameters we obtained: $\gamma_{\Psi a}=21.1^{\circ} ; \Psi_{m}=0.938 \mathrm{~Wb} ; E_{a}=208 \mathrm{~V}$; $\varphi_{E a}=66.1^{\circ} ; P_{\text {mag }}=1.906 \mathrm{~kW} ; R_{\text {mag }}=3.04 \mathrm{~m} \Omega ; \varphi_{s}=65.8^{\circ}$. At the same time, the image shown in Fig. 1 is an obtained vector picture of the magnetic flux density, and in addition Fig. 3 shows an obtained picture of field lines. Here, the direction of the vectors of magnetic quantities is given, and their position angles are shown, including the magnetic flux density vector $\boldsymbol{B}$ in the center of the chamber. Its angle is determined by the coordinate components of the magnetic flux density $B_{x}$ and $B_{y}$ : $\alpha_{B}=\operatorname{arctg}\left(B_{x} / B_{y}\right)=15.1^{\circ}$.

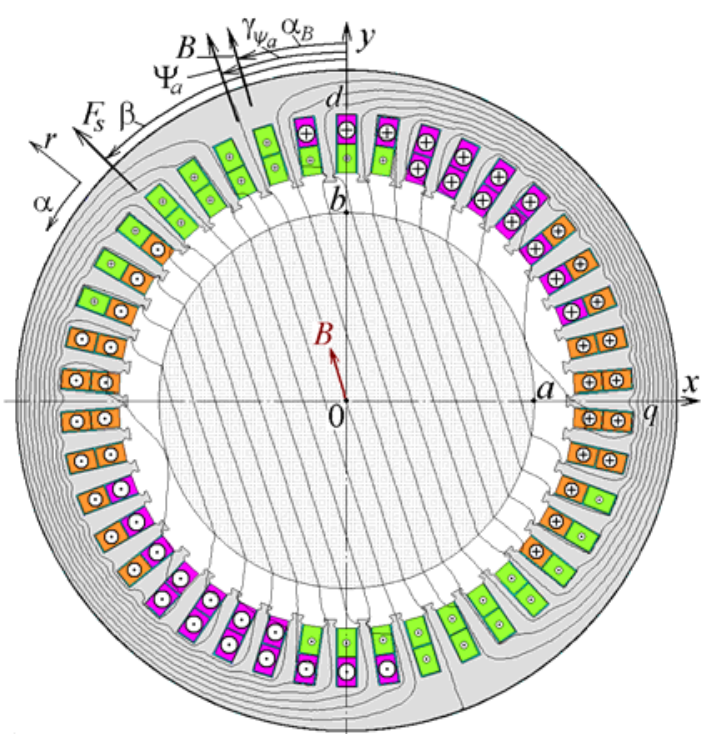

Fig. 3. Magnetic field lines and directions of vectors of magnetic quantities

An interesting fact is that the angle $\gamma_{\Psi a}$ turned out to be noticeably smaller than the angle $\beta$. In addition, it was found that for $\beta=0$, the angle $\gamma_{\Psi a}$ also has a zero value, and this corresponds to the idle mode, because the EMT, as shown below, is also equal to zero. The angle of displacement of the MFL vector $\underline{\Psi}_{a}$ during the transition from the idle to the load, according to the well-known theory of synchronous electric machines, is called the angle of load $\Theta$. Therefore, the angle $\gamma_{\Psi a}$ marked in Fig. 3, is the angle of the load of the inductor, that is, we can assume: $\Theta=\gamma_{\Psi a}$.

Based on the calculation of the magnetic field and the identification of phase (angular) and quantitative relations of electrical and magnetic quantities, we can proceed to determine the energy parameters of the inductor.

Directly by the distribution of the radial $B_{r}$ and angular $B_{\alpha}$ components of the magnetic flux density using the FEMM software [8], through the Maxwell magnetic tension tensor, the rotating EMT is obtained, which is essentially reactive:

$$
M_{e m}=\frac{l_{a}}{\mu_{0}\left(r_{s i}-r_{r e}\right)} \int_{S_{\delta}} r B_{r} B_{\alpha} d S,
$$

where $S_{\delta}$ is the cross-sectional area of the gap bounded by the radii $r_{r e}$ and $r_{s i} ; \mu_{0}$ is the magnetic constant.

The output, i.e. useful inductor power is obtained in the mechanical relationship:

$$
P_{\text {out }}=M_{\text {em }} \omega_{s} / p
$$

Through electrical quantities, electromagnetic power is obtained:

$$
P_{e m}=m_{s} E_{a} I_{s} \cos \varphi_{E a} .
$$

Power consumption from the mains - input power:

$$
P_{\text {in }}=m_{s} U_{s} I_{s} \cos \varphi_{s} \text {. }
$$

The power losses in the inductor are the sum of the aforementioned magnetic losses power $P_{\text {mag }}$ and the electric losses power in the stator winding:

$$
P_{e l}=m_{s} R_{s} I_{s}^{2} \text {. }
$$
is found:

By determined powers, the efficiency of the inductor

$$
\eta=P_{\text {out }} / P_{\text {in }}
$$

Variants of the inductor operation in load mode and the principles of their calculation. When the mode of operation of the inductor changes, concomitant changes in the quantitative-phase ratios of electric and magnetic quantities occur in it. To obtain the characteristics of the inductor, it is necessary to maintain the values of the basic quantities, vary one of the quantities accepted as an argument, and calculate other values- functions.

The initial (generalized) phase of currents $\beta$, which is included in (1), is accepted as a variable quantity, which, when the inductor operates, is automatically set depending on the level of its load.

Operation of the inductor is possible in two variants with the corresponding basic values:

1) when stabilizing the effective value of the current $I_{s}$, that is, $I_{s}=$ const;

2) when stabilizing the similar voltage value $U_{s}$, that is, $U_{s}=$ const.

In the first variant, by varying the angle $\beta$ for each of its values, the direct problem is in fact solved: for a given current $I_{s}$, the magnetic field is calculated and the necessary parameters of the inductor including the voltage $U_{s}$ are obtained from the sequence of formulas (1)-(9). 
In the second variant, for a given voltage including the voltage $U_{s}$, for each angle $\beta$, the inverse problem is solved with the result of obtaining a number of parameters of the inductor, as well as the current $I_{s}$ unknown in this case.

The solution of the inverse problem is more complicated and is obtained by the method of successive approximations with the solution of the direct problem at each iteration.

For such a solution, for each new value of the angle $\beta$, the initial approximation of the current $I_{s, 1}$ is set (for example, it can be taken from the experience of previous calculations) and the magnetic field is calculated, and then the voltage value $U_{s, 1}$ is obtained from (7).

After the first and each subsequent iterative steps, a new value of the stator current is determined by linear interpolation or extrapolation:

$$
I_{s, n i+1}=I_{s, n i-1}+\frac{I_{s, n i}-I_{s, n i-1}}{U_{s, n i}-U_{s, n i-1}}\left(U_{s}-U_{s, n i-1}\right),
$$

where $n i, n i-1, n i+1$ are the numbers of the current, previous and next iterations, respectively.

At the first iteration, the number of the previous iteration is $n i-1=0$, for which $I_{s, 0}=0$ and $U_{s, 0}=0$ are accepted, and the values of $I_{s, 1}$ and $U_{s, 1}$ are already prepared.

At the subsequent iteration, the value $I_{f o, n i}+1$ obtained by (16) already plays the role of $I_{s, n i}$, and the previous value of $I_{s, n i}$ plays the role of $I_{s, n i-1}$. And again, for the updated current $I_{s, n i}$ the magnetic field and phase voltage $U_{s, n i}$ are calculated using formulas (1)-(9).

After the next iteration, the voltage mismatch with its specified value $U_{s}$ is determined:

$$
d U_{s}=\frac{\operatorname{abs}\left(U_{s}-U_{s, n i+1}\right)}{U_{s}} .
$$

Iterations continue until the specified accuracy of the solution $d U_{s, \max }$ is obtained, i.e.

$$
d U_{s}<d U_{s, \max } \text {. }
$$

The last value $I_{s, n i+1}-$ this is the current $I_{s}$ at which the value of $U_{s}$ will be provided.

For example, at $\beta=45^{\circ}$, after setting the initial value of the current $I_{s, 1}=500 \mathrm{~A}$, the values $I_{s}=455 \mathrm{~A}$ and $d U_{s}=0.0005$ p.u. (for these calculations, this is even excessive accuracy) were obtained in four iterations.

To identify the quantitative-phase relationships of the values, calculations were performed for the two variants of operation of the inductor noted above in the text. This is done with four values of the angle $\beta: 0,30^{\circ}$, $60^{\circ}$ and $90^{\circ}$. The obtained currents, MFLs, and voltages are presented in vector form in Fig. 4 in compliance with the proportions for the same values.

When stabilizing the current, its value is taken as in the above calculation of the parameters of the inductor at $U_{s}=220 \mathrm{~V}$ and $\beta=45^{\circ}$, i.e. $I_{s}=455 \mathrm{~A}$.

When stabilizing the voltage, its value is assumed to be nominal, that is, $U_{s}=220 \mathrm{~V}$.

It turned out that the vectors of the current and the MFL coincide in phase only at extreme values of $\beta$ - at 0 and $90^{\circ}$. For all other angles (and not only those considered), the MFL vector $\underline{\Psi}_{a}$ substantially lags in phase from the current vector $\underline{I}_{s}$, as was already shown in Fig. 3.

At $I_{s}=$ const (Fig. 4,a), with an increase in the angle $\beta$, the values of the MFL and the required voltage $U_{s}$ significantly decrease. At $U_{s}=$ const (Fig. 4,b), with an increase in the angle $\beta$, the MFL values are also stable, but the required current $I_{S}$ significantly increases.

Figure 4 shows the load angle of the inductor $\Theta$, which is counted from the position of the MFL vector $\underline{\Psi}_{a, 0}$, corresponding to idle, to the position $\underline{\Psi}_{a}$, corresponding to any load level. The essence of this angle was discussed above in relation to Fig. 3.

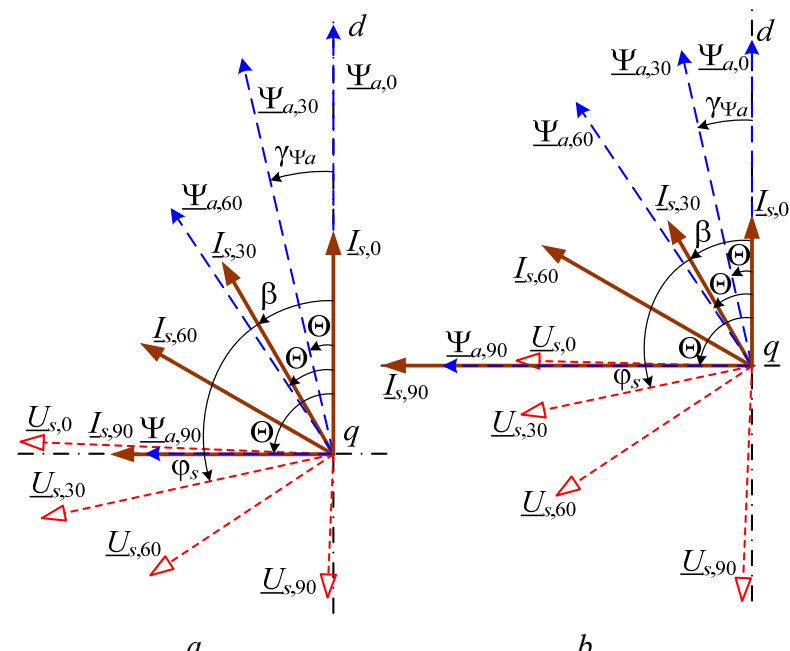

Fig. 4. System of vectors of current vectors, MFL, and voltage at angles $\beta-0,30^{\circ}, 60^{\circ}$ and $90^{\circ}$ marked in the indices: $a-I_{s}=$ const $b-U_{s}=$ const

Characteristics of the inductor. The above theoretical provisions allow to obtain a family of characteristics of the inductor, which connect its electrical, magnetic, energy and phase (angular) parameters when operating in load mode.

The characteristics of the inductor during operation with stabilization of the stator winding current are considered in [7]. In continuation of these studies, this paper further presents the characteristics of the operation of the inductor with a stable supply voltage. For this mode, you can do without a regulator, using the available mains. However, in this case, the stator winding current must be limited by one - the maximum allowable load. And in the possible range of operation of the inductor with a reduced load, the stator winding will operate with incomplete use of current.

In general, the characteristics show a change in a number of quantities describing the operation of the inductor when its load changes. They can occur with a change in the filling of the working chamber or for other reasons, accompanied by a change in the mechanical moment of resistance from the side of the processed substance. Due to the well-known self-regulation property inherent in electric motors, the corresponding EMT is automatically set. With a stable value of the stator winding voltage, this occurs due to a change in the winding current, load angle, and other phase ratios of electrical and magnetic quantities. 
To form the characteristics of the inductor, as was noted, in the calculations, the angle of the initial phase of the currents $\beta$ included in (1) was varied. And to obtain integral characteristics, the angle range from 0 to $90^{\circ}$ was adopted, which was passed with a step of $5^{\circ}$, which gave sufficient «smoothness» of the graphs.

A whole set of characteristics calculated for $U_{s}=$ const, which may be of interest to inductor developers, is shown in Fig. 5-8. The essence of the characteristics is manifested by specific values, which are indicated on the graphs.

The main input values for the inductor are the voltage of the stator winding and its current, the output value is the rotating EMT (10). Figure 5 summarizes the characteristics of such quantities, and, for comparison, the mode $I_{s}=$ const is added to the mode $U_{s}=$ const, and the argument $\beta$ is replaced by the load angle $\Theta$ - respectively, Fig. 6.

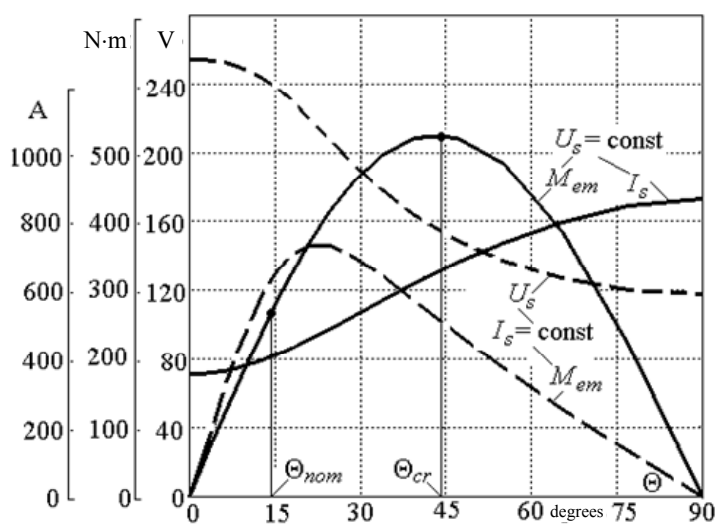

Fig. 5. Angular characteristics for calculation variants $U_{s}=$ const and $I_{s}=$ const and related changes in $I_{s}$ and $U_{s}$

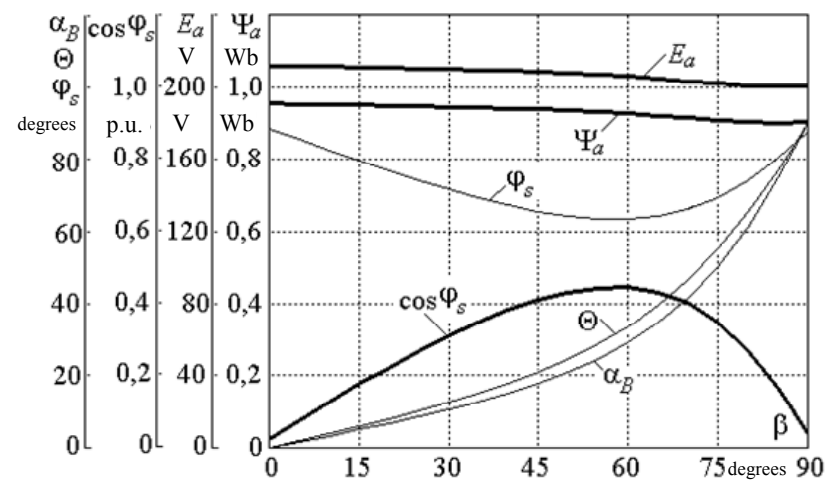

Fig. 6. Characteristics of magnetic flux linkage, EMF, phase relationships and power factor

In this way, the angular characteristic $M_{e m}(\Theta)$, known in the theory of synchronous machines, was obtained for the inductor. And in this case, such a characteristic for the mode $U_{s}=$ const has a classical form - a half-wave of a sine wave of double frequency, which is typical for synchronous reluctance motors.

It can be noted that the mode $U_{s}=$ const is more effective from the point of view of obtaining EMT, which should ensure the implementation of the technological process of processing substances. This reinforces the mentioned advantage of this mode - the absence of a voltage regulator, and the necessary current will be set based on the self-regulation property of the inductor inherent in electric motors.

Note that in Fig. 5 at the initial $(\beta=0)$ and final $\left(\beta=90^{\circ}\right)$ points, the EMT is zero, i.e., here the idle mode imagined earlier a priori takes place. The values of angles $\beta$ and $\Theta$ coincide only at these points (Fig. 6), and within the range, the angle $\Theta$ is smaller than $\beta$.

The maximum EMT (Fig. 5) was obtained at a critical load angle $\Theta_{c r}$ equal to $44.5^{\circ}$, and this in Fig. 6 corresponds to the angle $\beta=67^{\circ}$. In the range of the angle $\Theta$ from 0 to $\Theta_{c r}$, according to the theory of synchronous electric machines, the operation of the inductor is stable. For a twofold margin in torque, it can be taken from Fig. 5 as a nominal load angle $\Theta_{\text {nom }}$ equal to $14^{\circ}$, and it in Fig. 6 corresponds to the angle $\beta=33^{\circ}$.

In Fig. 5, 6 it is revealed that from $\beta=0$ (idle mode) to the angle $\beta=33^{\circ}$ current, MFL, EMF are quite stable. Further, an increase in load leads to a significant increase in current, which is accompanied by a corresponding increase in EMT and a certain decrease in EMF and MFL included in (6) and (7). Due to the stability of the MFL, the magnetic losses are stable, and the electric losses (14) increase along with the current (Fig. 7).

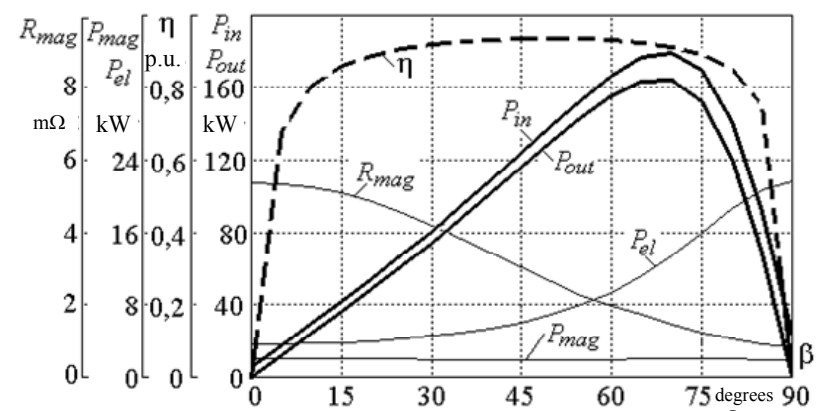

Fig. 7. Characteristics of the input and output powers of the inductor and its power losses, efficiency and active resistance taking into account magnetic losses

The powers in the mechanical (11) $P_{\text {out }}$ (Fig. 7) and electrical (12) expressions were identical. This can be considered a check of the adequacy of the phase relationships of the considered electrical quantities. Note that the graph of the EMT function $M_{e m}(\beta)$ is similar in shape to the graph of these powers in Fig. 5, which is natural in view of their connection according to (11).

The graphs of the characteristics of the efficiency (Fig. 7) $\eta$ and the power factor $\cos \varphi_{s}$ (Fig. 6) show their increase with increasing load of the inductor. In the range of stable operation, the efficiency level corresponds to electric machines of small and medium power. At the same time, the level of $\cos \varphi_{s}$ values is very low, and this is explained by the increased magnetizing component of the stator winding current due to the low-magnetic medium of the working chamber and significant air gap.

Figure 8 shows the functions of changing the magnetic flux density at points $0, a$ and $b$, marked in Fig. 3. Firstly, the proximity of the values of magnetic flux density in different places of the chamber is visible, and secondly, their stability in the operating range of the load of the inductor. 
By comparing the characteristics of the inductor in the operation mode calculated here at $U_{s}=$ const, and the mode presented in [7] at $I_{s}=$ const, one can identify certain advantages and disadvantages of each of them.

From the point of view of such important characteristics as power factor and efficiency, the operation modes of the inductor $U_{s}=$ const and $I_{s}=$ const turned out to be almost equivalent.

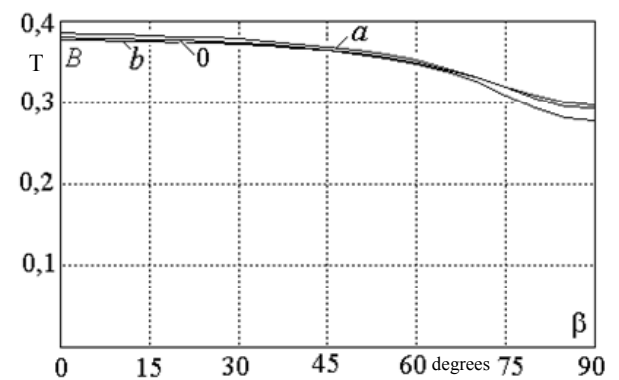

Fig. 8. Magnetic flux density $B$ characteristics at certain points of the working chamber of the inductor

Another important requirement for «processors» of various substances is the uniformity and stability of magnetic flux density in the working area, while working in the mode $U_{s}=$ const it is provided much better.

\section{Conclusions.}

1. The developed technique based on numerical calculations of magnetic fields allows to organize an iterative process for the calculation analysis of the characteristics of an inductor operating with a changing load with a stable supply voltage of its winding.

2. For a test sample of the inductor, when operating in the load mode with the condition of stabilizing the voltage of its winding, the electric, magnetic and energy parameters, as well as phase (angular) relationships of the operation quantities are calculated and presented. Their interconnections made it possible to form a family of characteristics with an argument - a phase shift of the MMF of the stator winding in relation to the longitudinal axis of its working chamber.

3 . In view of the simultaneous calculation of a number of parameters of the inductor, one can also obtain a variety of its characteristics by choosing any of these parameters instead of the argument $\beta$.

4. A comparison is made of the angular characteristics of the inductor, calculated by methods that provide stabilization of the voltage or current of the stator winding. More rational for the operation of the inductor is the voltage stabilization mode, which in the desired operating range of the load angle up to $25^{\circ}$ provides its best and electrical, magnetic, force and energy parameters.

\section{REFERENCES}

1. Chen L., Yang R., Zeng J., Shao Y., Xiao Q., Guo S. A wet belt permanent high gradient magnetic separator for purification of non-metallic ores. International Journal of Mineral Processing, 2016, vol. 153, pp. 66-70. doi: 10.1016/j.minpro.2016.06.004.

2. Ge W., Encinas A., Araujo E., Song S. Magnetic matrices used in high gradient magnetic separation (HGMS): A review. Results in Physics, 2017, vol. 7, pp. 4278-4286. doi: 10.1016/j.rinp.2017.10.055.

3. Wang Y., Gao D., Zheng X., Lu D., Li X. Rapid determination of the magnetization state of elliptic cross-section matrices for high gradient magnetic separation. Powder Technology, 2018, vol. 339, pp. 139-148. doi: 10.1016/j.powtec.2018.08.012.

4. Altın G., Inal S., Ibrahim A.L.P. Recovery of chromite from processing plant tailing by vertical ring and pulsating high gradient magnetic separation. MT Bilimsel, 2018, vol. 13, pp. 23-35.

5. Gerasimov M.D., Loktionov I.O. Dual-use technological solutions. Application prospects. Vektor GeoNauk, 2019, vol. 2, no. 1, pp. 19-26. doi: 10.24411/2619-0761-2019-10003.

6. Milykh V.I., Shilkova L.V. Experimental research of the three-phase physical model of the magnetic field inductor in the working mode when processing bulk material. Bulletin of NTU "KhPI». Series: "Electric machines and electromechanical energy conversion», 2020, no.3(1357), pp. 3-7. (Ukr). doi: 10.20998/2409-9295.2020.3.01.

7. Milykh V.I., Shilkova L.V. Numerical-field analysis of the characteristics of a three-phase magnetic field inductor for the treatment of various substances with current stabilization. Electrical engineering \& electromechanics, 2019, no. 6, pp. 21 28. doi: 10.20998/2074-272X.2019.6.03.

8. Finite Element Method Magnetics: OldVersions. FEMM 4.2 11 Oct2010 Self-Installing Executable. Available at: http://www.femm.info/wiki/OldVersions (accessed 15.06.2017).

9. Milykh V.I. The system of automated formation of electrical machines computational models for the FEMM software environment. Technical Electrodynamics, 2018, no.4, pp. 74-78. (Ukr.) doi: 10.15407/techned2018.04.074.

Received 02.01.2020

V.I. Milykh ${ }^{1}$, Doctor of Technical Science, Professor,

L.V. Shilkova ${ }^{1}$, Postgraduate Student,

${ }^{1}$ National Technical University «Kharkiv Polytechnic Institute»,

2, Kyrpychova Str., Kharkiv, 61002, Ukraine,

e-mail:mvikemkpi@gmail.com, larisa_lv@ukr.net

How to cite this article:

Milykh V.I., Shilkova L.V. Characteristics of a cylindrical inductor of a rotating magnetic field for technological purposes when it is powered from the mains at a given voltage. Electrical engineering \& electromechanics, 2020, no.2, pp. 13-19. doi: 10.20998/2074-272X.2020.2.02. 